\title{
Rebound Tonometry in Cataract Surgery: Comparison with Goldmann Applanation Tonometry
}

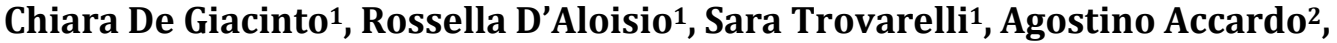 Odilla Vattovani ${ }^{1}$, Daniele Tognetto ${ }^{1}$}

\author{
${ }^{1}$ Department of Medicine, Surgery and Health Sciences, University of Trieste, Trieste, Italy \\ ${ }^{2}$ Department of Industrial and Information Technology, University of Trieste, Trieste, Italy \\ Email: *ross. da loisio@gmail.com
}

How to cite this paper: De Giacinto, C., D'Aloisio, R., Trovarelli, S., Accardo, A., Vattovani, O. and Tognetto, D. (2018) Rebound Tonometry in Cataract Surgery: Comparison with Goldmann Applanation Tonometry. Open Journal of Ophthalmol$o g y, 8,1-11$.

https://doi.org/10.4236/ojoph.2018.81001

Received: September 24, 2017

Accepted: January 5, 2018

Published: January 8, 2018

Copyright $(9) 2018$ by authors and Scientific Research Publishing Inc. This work is licensed under the Creative Commons Attribution International License (CC BY 4.0).

http://creativecommons.org/licenses/by/4.0/

\begin{abstract}
Purpose: to compare the rebound tonometer ICare ${ }^{\oplus}$ (RT) with the Goldmann applanation tonometer (GAT) in cataract surgery and to assess the influence of central corneal thickness (CCT) on intraocular pressure (IOP) measurements. Design: retrospective, comparative study. Methods: a total of $472 \mathrm{pa}-$ tients underwent IOP measurement using RT (time $0=\mathrm{RTa}$ ). GAT IOP measurement was performed 5 minutes later, followed by a second RT IOP measurement after other 5 minutes $(\mathrm{RTa}+10 \mathrm{~min}=\mathrm{RTb})$. CCT was obtained by ultrasound pachymetry. In 106 patients IOP was measured by means of RT and GAT before clear corneal cataract surgery (RT1 and GAT1) and at one day postoperatively (RT2 and GAT2). Results: RT IOP values $>5 \mathrm{mmHg}$ were overestimated, while RT IOP values $<15 \mathrm{mmHg}$ were underestimated. Every $100 \mu \mathrm{m}$ of CCT an increase of $0.97 \mathrm{mmHg}$ and $0.33 \mathrm{mmHg}$ was found for RT and GAT respectively. The difference between RT1 and RT2, GAT1 and GAT2, RT1 and GAT1 was not statistically significant; while the difference between RT2 and GAT2 was statistically significant ( $p<0.04)$. The difference between RTa and RTb was not statistically significant whereas the difference between RTa and GAT and RTb and GAT was statistically significant $(\mathrm{p}<0.001)$. Conclusion: our results showed a good agreement between measurements obtained with RT and GAT in pre and postoperative cataract surgery, although a significant statistically difference was found between RT and GAT measurements performed postoperatively. Moreover, CCT is a parameter to be considered for the IOP measurement, especially for values obtained with RT.
\end{abstract}

\section{Keywords}

Applanation Tonometer, Cataract Surgery, Intraocular Pressure, Pachymetry, 


\section{Introduction}

High intraocular pressure (IOP) values are the most important risk factors for developing glaucomatous optic neuropathy (GON). Furthermore, IOP lowering is essential to prevent optic nerve damage or visual field deterioration [1] [2] [3] [4].

Therefore, accurate assessment of IOP is essential in the routinely clinical practice.

The Goldmann applanation tonometer (GAT) is still considered the gold standard instrument for IOP measurement [5]. This device infers IOP from the force required to flatten a predetermined area of the central cornea. It is already known GAT reading is influenced by modifications of the structure, the curvature and the central thickness of the cornea [6].

An ideal tonometer should have an excellent accuracy in intraocular pressure measurement in both normal and pathological conditions (e.g. corneal irregularity and post-keratoplasty). In addition, it should be minimally invasive, easily usable for all patients, including children and uncooperative patients.

Several new instruments have been introduced in order to overcome some of the GAT limitations such as the ICare ${ }^{\varpi}$ rebound tonometer (RT). The latter is portable, ease of use and even an operator with little experience can use it with confidence, since there is no need for any anaesthetic or fluorescein [7] [8].

RT device works on the principle of a rebound tonometry using an induction-based coil system to measure the motion parameters of a bouncing probe after colliding with the cornea [9] [10]. An advanced algorithm combined with a special software analyzes deceleration and the contact time of the probe while it touches the cornea.

The primary aim of this study was to evaluate the effect of cataract surgery on the IOP measurements performed with the rebound tonometer, as well as to assess the agreement between GAT and RT. Moreover, the effect of central corneal thickness (CCT) on IOP values was evaluated.

Finally, the influence of GAT in subsequent RT measurements was studied.

\section{Materials and Methods}

This was a retrospective and comparative study that adhered to the tenets of the Declaration of Helsinki. The study was approved by our Institutional Review Board of the Department of Medicine, Surgery and Health Sciences of Trieste and Trieste University Hospital, Italy.

We conducted a retrospective analysis of 472 medical records of 472 patients ( $60 \%$ female, $40 \%$ male) who were recruited at the Eye Clinic of Trieste, AOUTS Ospedali Riuniti of Trieste between December 2015 and December 2016. Their 
IOP was checked with the two commercially available devices: Goldmann applanation tonometer (AT900, Haag-Streit, Koeniz, Switzerland) and ICare ${ }^{\varpi}$ rebound tonometer (TAO1i-Tiolat Oy, Helsinki, Finland), as our routinely clinical practice. Data of one eye per subject was enrolled in the study, choosing randomly between the right and the left eye.

Mean age of all subjects was 75 years (range: 53 - 92) (Table 1).

Inclusion criteria were:

- age $<95$ years

- absence of anterior segment surgery or refractive surgery

- absence of corneal pathology

- absence of high refractive errors (myopia $>5 \mathrm{D}$, astigmatism $>2 \mathrm{D}$ )

Exclusion criteria were:

- corneal opacity

- glaucomatous and ocular hypertensive eyes

- history of previous retinal surgery

- history of previous ocular trauma

Intraocular pressure was measured with the two different tonometers: RT and GAT.

The tonometers used were regularly calibrated according to manufacturer's instructions. All measurements were performed by the same experienced examiner.

IOP readings were obtained as follows:

1) IOP was first measured by ICare rebound tonometry (RTa). This device provides an automatically average (d) IOP value, visible on the display after six consecutive measurements;

2) GAT was performed five minutes later, preceded by topical anaesthesia with $0.4 \%$ oxybuprocaine hydrochloride and the application of fluorescein paper - Haag-Streit, Koeniz, Switzerland. Two consecutive readings were obtained and a mean IOP value was calculated.

3) After 5 minutes GAT performing, a further measurement with the ICare $(\mathrm{RTb}=\mathrm{Rta}+10 \mathrm{~min})$ was taken.

For each patient CCT was measured by the same examiner. The CCT value was obtained for all subjects as an average of 5 consecutive readings taken with the Corneo-Gage Plus pachymeter (Sonogage, Cleveland, $\mathrm{OH}$ ).

Table 1. Patient demographics.

\begin{tabular}{cc}
\hline Characteristics & \\
\hline Number of eyes & 772 \\
Mean age (years) & 75 \\
Range & $53-92$ \\
Gender & \\
Men & 189 \\
Women & 283
\end{tabular}


In 106 eyes of 106 enrolled patients, who were to undergo cataract surgery the following day, IOP was measured by means of RT and GAT before (RT1 and GAT1) and after (RT2 and GAT2) the surgical procedure using the same scheme of tonometry as above described.

Patients with cataract surgery-related complications were excluded from the study.

Bland-Altman analysis was used to assess the clinical agreement of the IOP measurements obtained with the two different tonometers. Pearson correlation coefficient was determined to evaluate the relationship between CCT and IOP. The differences between the two tonometers in terms of IOP readings were compared with a paired t-test. The level of significance for each test was set at $\mathrm{p}<0.05$.

Shapiro-Wilk's test was performed to evaluate the departures from normality distribution for each variable.

Statistical analysis was performed using the statistical package SPSS Statistics v 17.0 software (SPSS Inc., Chicago, Illinois, USA).

\section{Results}

The IOP reading mean of 472 eyes analyzed was $14.40 \pm 3.98 \mathrm{mmHg}$ using RT, and $14.75 \pm 3.33 \mathrm{mmHg}$ using GAT. The mean of CCT consecutive readings was $557.5 \pm 45$ microns (Table 2, Figure 1).

Bland-Altman plot analysis (Figure 2$)$ revealed that the mean difference $( \pm 1$ Standard Deviation, SD) between RT and GAT measurements was $-0.35 \pm 2.82$ $\mathrm{mmHg}$.

The $95 \%$ limits of agreement between RT and GAT were -5.88 and $5.18 \mathrm{mmHg}$.

Although a good correlation between the values measured using the two different devices was found (Pearson correlation $r=0.72, r^{2}=0.51, p<0.001$ ), the difference between RT and GAT was statistically significant ( $\mathrm{p}<0.05$, t-test). RT IOP values $>15 \mathrm{mmHg}$ were overestimated, while RT IOP values $<15 \mathrm{mmHg}$ were underestimated (Figure 3).

The difference between RT1 and RT2, GAT1 and GAT2, RT1 and GAT1 was not statistically significant, while the difference between RT2 and GAT2 was statistically significant ( $\mathrm{p}<0.04)$ (Figure 4).

The results of the IOP mean values of RT1, RT2, GAT1 and GAT2 $( \pm$ SD) are described in Table 3.

Table 2. Mean and Standard deviation of central corneal thickness and intraocular pressure using rebound and Goldmann applanation tonometers.

\begin{tabular}{ccc}
\hline & Mean value & Standard deviation \\
\hline CCT & $557.5 \mu \mathrm{m}$ & \pm 45 \\
RT & $14.40 \mathrm{mmHg}$ & \pm 3.98 \\
GAT & $14.75 \mathrm{mmHg}$ & \pm 3.33 \\
\hline
\end{tabular}

a. Abbreviations: $\mathrm{CCT}=$ central corneal thickness; RT: rebound tonometer; GAT: Goldmann applanation tonometer. 

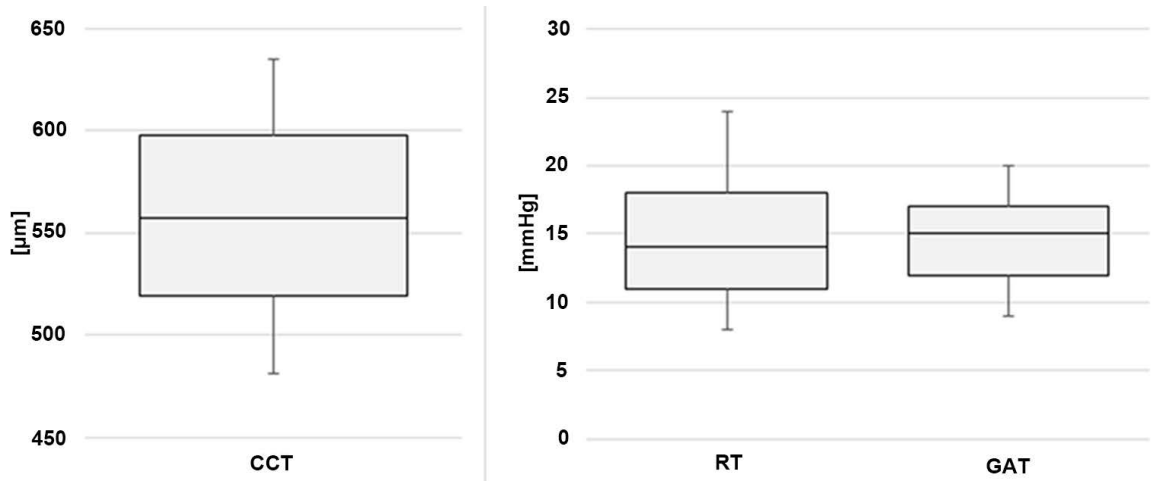

Figure 1. Box plot. Distribution of central corneal thickness and intraocular pressure values. a. Abbreviations: $\mathrm{CCT}=$ central corneal thickness; RT: rebound tonometer; GAT: Goldmann applanation tonometer.

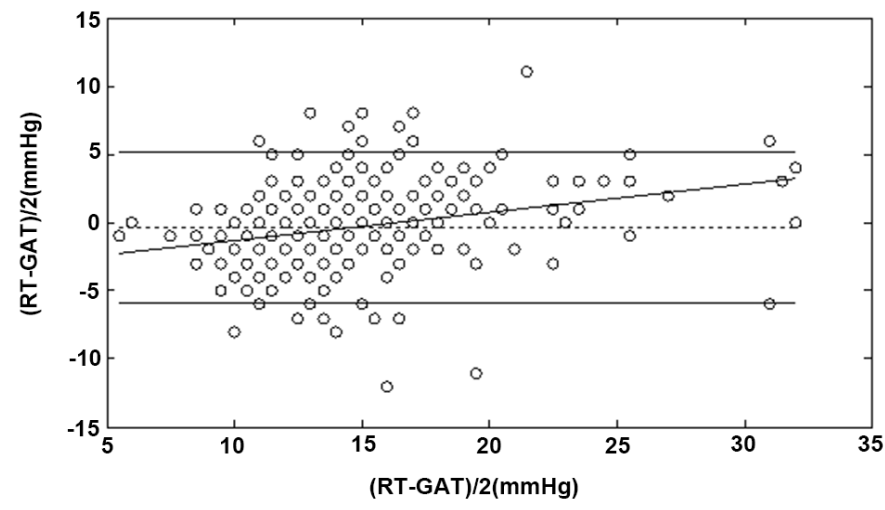

Figure 2. Bland-Altman plot: mean IOP $[(\mathrm{RT}+\mathrm{GAT}) / 2]$ versus their difference (RT- GAT). a. The mean difference \pm SD was $-0.35 \pm 2.82$ $\mathrm{mmHg}$. b. The $95 \%$ limits of agreement between RT and GAT were $-5.88 \sim 5.18 \mathrm{mmHg}$.

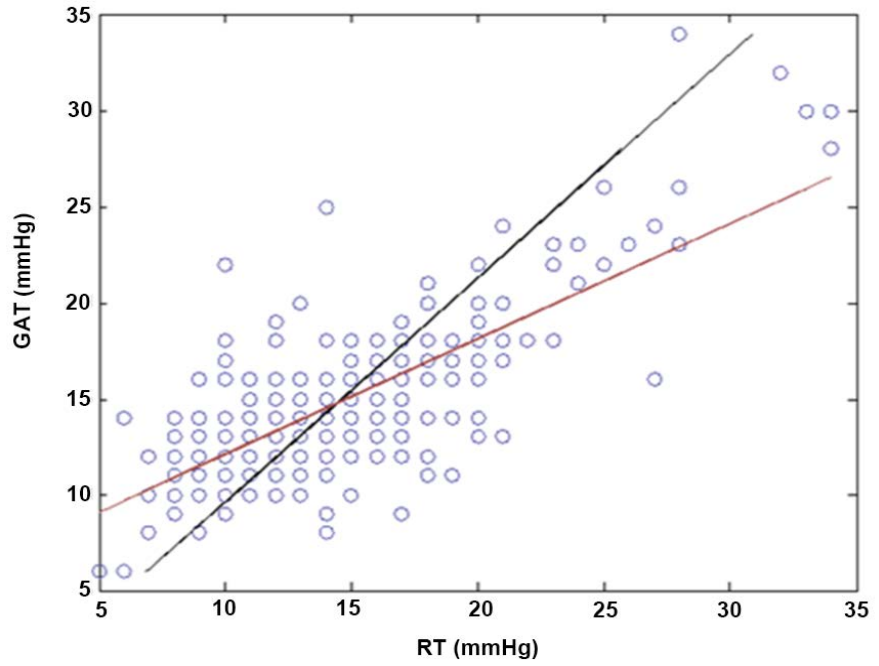

Figure 3. The graph shows the linear correlation of values obtained with RT and GAT. a. A good correlation $(r=0.72)$ between RT and GAT was found. $b$. The linear function is GAT $=0.60+6.10 \times \mathrm{RT}$ (red line), $\mathrm{RT}=0.85 \times \mathrm{GAT}+1.80$ (black line). 

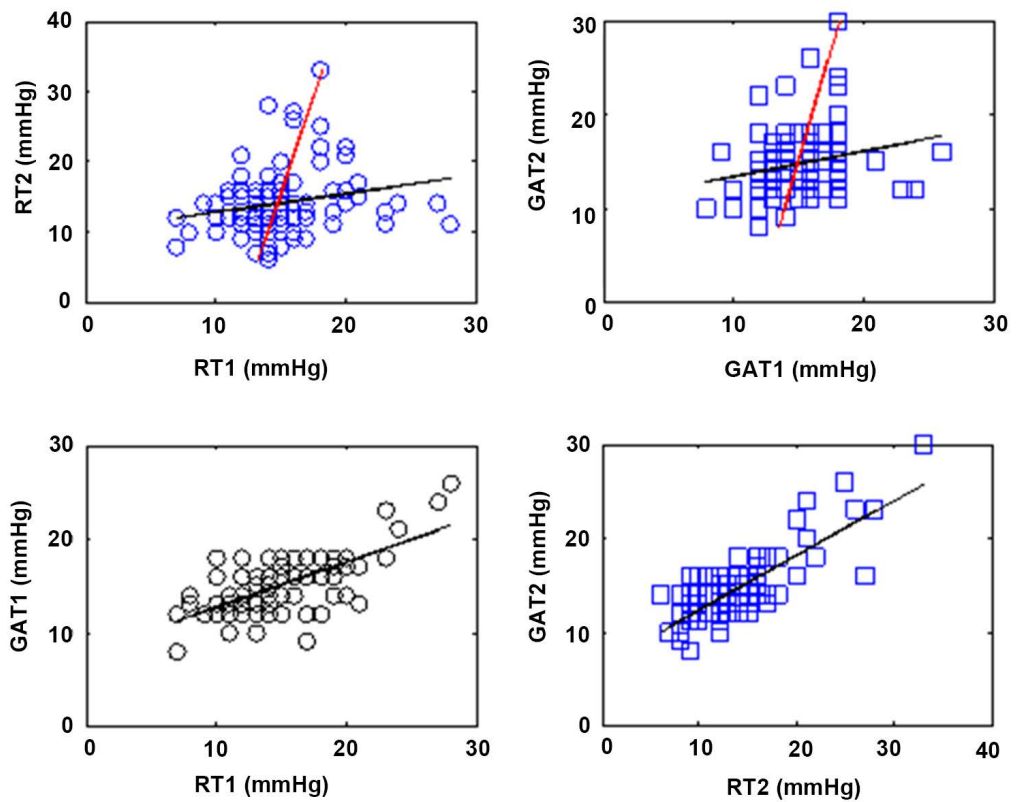

Figure 4. Comparison between IOP readings using RT and GAT before and after cataract surgery. a. t-test. b. Top left: RT1 vs RT2 ( $\mathrm{p}=0.16$; RT2 $=$ RT1 $\times$ $0.26+10.19 ; \mathrm{RT} 1=\mathrm{RT} 2 \times 0.18+12.17$; correlation coefficient $=0.22)$; top right: GAT1 vs GAT2 $(\mathrm{p}=0.4$; GAT2 $=$ GAT1 $\times 0.27+10.5$; GAT1 $=$ GAT2 $\times$ $0.21+11.87$; correlation coefficient $=0.24)$; bottom left: RT1 vs GAT1 ( $\mathrm{p}=$ 0.5 ; GAT1 $=0.48 \times \mathrm{RT} 1+7.81$; correlation coefficient $=0.62)$; bottom right: $\mathrm{RT} 2$ vs GAT2 $(\mathrm{p}=\mathbf{0 . 0 3 4}, \mathrm{GAT} 2=0.59 \times \mathrm{RT} 2+6.38$; correlation coefficient $=$ $0.78)$.

Table 3. Mean and Standard deviation of intraocular pressure using rebound and Goldmann applanation tonometers before and after cataract surgery.

\begin{tabular}{ccc}
\hline & \multicolumn{2}{c}{ Intraocular pressure } \\
\hline & Mean value & Standard deviation \\
\hline RT1 & $14.74 \mathrm{mmHg}$ & \pm 3.76 \\
RT2 & $14.04 \mathrm{mmHg}$ & \pm 4.48 \\
GAT1 & $14.93 \mathrm{mmHg}$ & \pm 2.94 \\
GAT2 & $14.62 \mathrm{mmHg}$ & \pm 3.36 \\
\hline
\end{tabular}

a. Intraocular pressure mean values of rebound tonometer before cataract surgery (RT1), rebound tonometer after cataract surgery (RT2), Goldmann applanation tonometer before cataract surgery (GAT1) and Goldmann applanation tonometer after cataract surgery (GAT2).

Moreover, a low correlation between RT reading and CCT was found (Pearson correlation $\mathrm{r}=0.11$ ), while the relationship between GAT reading and CCT had a very weak correlation coefficient (Pearson correlation $r=0.045$ ). Every $100 \mu \mathrm{m}$ of CCT an increase of $0.97 \mathrm{mmHg}$ and $0.33 \mathrm{mmHg}$ was found for the RT and GAT respectively (Figure 5).

The difference between RTa and RTb was not statistically significant ( $\mathrm{p}>0.13$, t-test), whereas the difference between RTa and GAT and RTb and GAT was statistically significant $(\mathrm{p}<0.001)$ and their correlation coefficients were 0.72 and 0.78 respectively (Figure 6 ). 

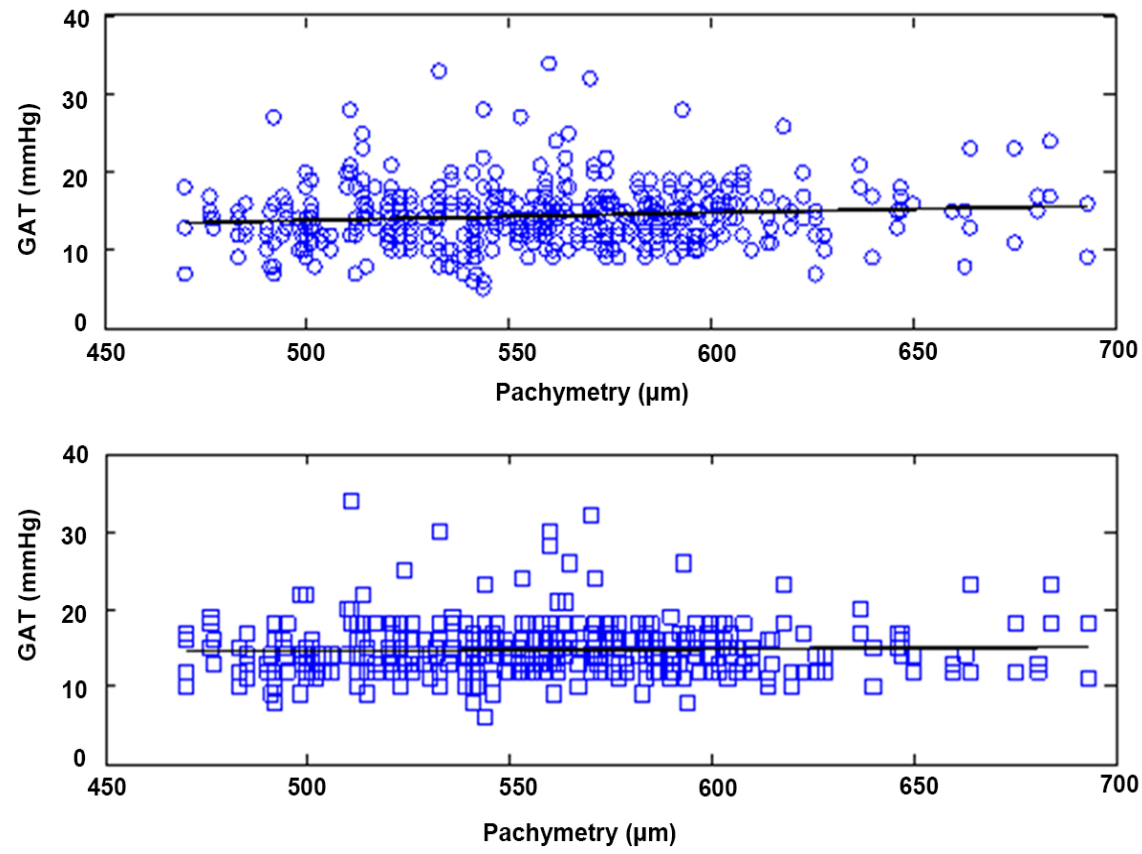

Figure 5. Correlation of rebound tonometer (RT) and Goldmann applanation tonometer (GAT) with central corneal thickness (CCT). a. Pearson correlation.
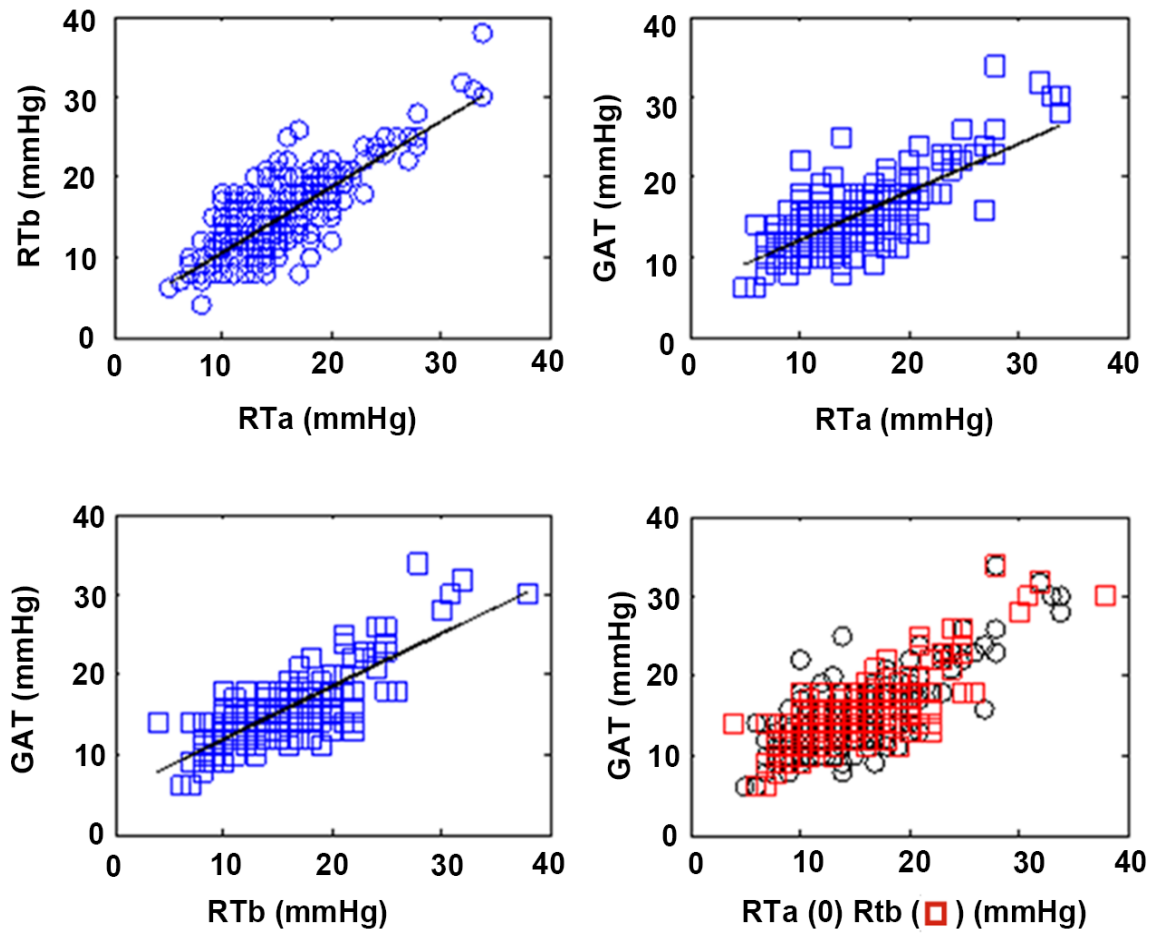

Figure 6. Comparison between series of IOP measurements using GAT and RT. a. $\mathrm{t}$-test $\mathrm{b}$. In the first graph, top left: $\mathrm{RTa}$ and $\mathrm{RTb}$ measurements are compared $(\mathrm{RTb}=$ $0.81 \times \mathrm{RTa}+2.52 ; \mathrm{r}^{2}=0.67 ;$ correlation coefficient $\left.=0.82 ; \mathrm{p}>0.13\right)$. Top right: $\mathrm{RTa}$ vs GAT $\left(\mathrm{GAT}=0.60 \times \mathrm{RTa}+6.10 ; \mathrm{r}^{2}=0.51\right.$; correlation coefficient $\left.=0.72 ; \mathrm{p}<0.001\right)$. Bottom left: RTb vs GAT $\left(\mathrm{GAT}=0.66 \times \mathrm{RTb}+5.34 ; \mathrm{r}^{2}=0.61\right.$; correlation coefficient $=0.78 ; \mathrm{p}<0.001)$. 


\section{Discussion}

Nowadays, RT has become an excellent alternative of GAT in clinical practice for IOP reading due to its accuracy and ease of use. Kontiola et al. [9] were the first who studied the Icare tonometer performance in animals suggesting that RT is a reliable and non-invasive instrument for IOP reading.

Nevertheless, the comparison between RT and GAT performed in the Fernandes's study [11] showed a significant difference between the two devices because of the IOP overestimation with the ICare. Therefore, IOP values obtained with the rebound tonometer should be re-assessed or be referred to GAT evaluation due to the high number of false positives found with the RT.

The aim of the present study was to compare rebound with applanation tonometers and to identify possible elements influencing the measurements of IOP, such as cataract surgery, central corneal thickness and corneal applanation after previous applanation tonometry.

Literature provides conflicting results concerning the comparison of the two instruments, related to the different characteristics of the subjects enrolled, the time elapsing between the several tonometries and the number of measurements for the final average value considered [12]-[29].

In the present study a good agreement of IOP readings between the two different tonometers was detected, as it has widely reported in literature [16] [17] [18].

These findings suggested RT may be a valid alternative to GAT, especially in uncooperative patients, children or wheelchair subjects who may have difficulties in positioning correctly on the slit lamp. Nevertheless, our results showed a statistically significant difference between RT and GAT IOP measurements, with a RT slight overestimation of IOP values over $15 \mathrm{mmHg}$ and an underestimation of those below $15 \mathrm{mmHg}$.

The overestimation of the rebound tonometer may be related to a systematic proportional error in the use of RT, since the difference between the two instruments increases as IOP rises.

Previous studies [20] [30] have already suggested a similar trend of RT.

Concerning the comparison between RT before and after GAT measurement, the results demonstrated that the applanation tonometry does not affect subsequent measurements with rebound tonometry.

Although a weak correlation between CCT and the two different tonometers was found, CCT is one of the parameters to be considered in tonometry, especially when it is performed using RT. The latter is more affected by CCT than GAT, as already reported by other authors [21] [22] [23] [24].

Our study mainly focused on the effects of cataract surgery on intraocular pressure measurement and on the comparison between rebound and applanation tonometry pre and postoperatively. In literature [31] changes in intraocular pressure after cataract surgery have already been described, in particular the IOP-lowering effect.

In addition, cataract surgery procedure may change the biomechanical prop- 
erties [12] [31] [32] [33] of the cornea, thus influencing the postoperative IOP reading as well as it may increase the difference between IOP values obtained with applanation and rebound tonometers.

In our work the rebound tonometer appears to be not so reliable since it differed significantly from GAT IOP values. Caution should be taken on the interpretation of the values obtained using the two different instruments, especially in cataract surgery.

Our study underlines that the two tools are quite concordant but they cannot be considered interchangeable in the clinical practice, in particular in the postsurgical follow up of cataract patients.

Nevertheless, further works will be necessary to better understand and to confirm the same conclusions related to rebound tonometry accuracy in cataract surgery.

\section{References}

[1] Grodum, K., Heijl, A. and Bengtsson, B. (2002) A Comparison of Glaucoma Patients Identified through Mass Screening and in Routine Clinical Practice. Acta Ophthalmologica Scandinavica, 80, 627-631. https://doi.org/10.1034/j.1600-0420.2002.800613.x

[2] Heijl, A., Leske, M.C., Bengtsson, B., Hyman, L., Bengtsson, B. and Hussein, M. (2002) Early Manifest Glaucoma Trial Group. Reduction of Intraocular Pressure and Glaucoma Progression: Results from the Early Manifest Glaucoma Trial. Archives of Ophthalmology, 120, 1268-1279. https://doi.org/10.1001/archopht.120.10.1268

[3] Kass, M.A. and Gordon, M.O. (2000) Intraocular Pressure and Visual Field Progression in Open-Angle Glaucoma. American Journal of Ophthalmology, 130, 490-491. https://doi.org/10.1016/S0002-9394(00)00658-9

[4] Leske, M.C., Heijl, A., Hyman, L. and Bengtsson, B. (1999) Early Manifest Glaucoma Trial Group. Early Manifest Glaucoma Trial: Design and Baseline Data. Oph thalmology, 106, 2144-2153. https://doi.org/10.1016/S0161-6420(99)90497-9

[5] Elmallah, M.K. and Asrani, S.G. (2008) New Ways to Measure Intraocular Pressure. Current Opinion in Ophthalmology, 19, 122-126. https://doi.org/10.1097/ICU.0b013e3282f391ae

[6] Moreno-Montañés, J., García, N., Fernández-Hortelano, A. and García-Layana, A. (2007) Rebound Tonometer Compared with Goldmann Tonometer in Normal and Pathologic Corneas. Cornea, 26, 427-430. https://doi.org/10.1097/ICO.0b013e318030df6e

[7] Detry-Morel, M., Jamart, J., Detry, M.B., Pourjavan, S., Charlier, L., Dethinne, B., et al. (2006) Clinical Evaluation of the Dynamic Rebound Tonometer ICare. Journal Francais D'Ophtalmologie, 29, 1119-1127. https://doi.org/10.1016/S0181-5512(06)73907-9

[8] Abraham, L.M., Epasinghe, N.C., Selva, D. and Casson, R. (2008) Comparison of the ICare Rebound Tonometer with the Goldmann Applanation Tonometer by Experienced and Inexperienced Tonometrists. Eye, 22, 503-506. https://doi.org/10.1038/sj.eye.6702669

[9] Kontiola, A.I., Goldblum, D., Mittag, T. and Danias, J. (2000) The Induction/Impact Tonometer: A New Instrument to Measure Intraocular Pressure in the Rat. Experimental Eye Research, 73, 781-785. https://doi.org/10.1006/exer.2001.1088 
[10] Kontiola, A.I. (2000) A New Induction-Based Impact Method for Measuring Intraocular Pressure. Acta Ophthalmologica Scandinavica, 78, 142-145. https://doi.org/10.1034/j.1600-0420.2000.078002142.x

[11] Fernandes, P., Díaz-Rey, J.A., Queirós, A., Gonzalez-Meijome, J.M. and Jorge, J. (2005) Comparison of the ICare Rebound Tonometer with the Goldmann Tonometer in a Normal Population. Ophthalmic and Physiological Optics, 25, 436-440. https://doi.org/10.1111/j.1475-1313.2005.00327.x

[12] Jorge, J.M., Gonzalez-Meijome, J.M., Queiros, A., Fernandes, P. and Parafita, M.A. (2008) Correlation between Corneal Biomechanical Properties Measured with the Ocular Response Analyzer and ICare Rebound Tonometry. Journal of Glaucoma, 17, 442-448. https://doi.org/10.1097/IJG.0b013e31815f52b8

[13] Rosentreter, A., Athanasopoulos, A., Schild, A.M., Lappas, A., Cursiefen, C. and Dietlein, T.S. (2013) Rebound, Applanation, and Dynamic Contour Tonometry in Pathologic Corneas. Cornea, 32, 313-318. https://doi.org/10.1097/ICO.0b013e318254a3fb

[14] Nakamura, M., Darhad, U., Tatsumi, Y., Fujioka, M., Kusuhara, A., Maeda, H., et al. (2006) Agreement of Rebound Tonometer in Measuring Intraocular Pressure with Three Types of Applanation Tonometers. American Journal of Ophthalmology, 142, 332-334. https://doi.org/10.1016/j.ajo.2006.02.035

[15] Iliev, M.E., Goldblum, D., Katsoulis, K., Amstutz, C. and Frueh, B. (2006) Comparison of Rebound Tonometry and Correlation with Central Corneal Thickness. British Journal of Ophthalmology, 90, 833-835. https://doi.org/10.1136/bjo.2005.089870

[16] Lopez-Caballero, C., Contreras, I., Muñoz-Negrete, F.J., Rebolleda, G., Cabrejas, L. and Marcelo, P. (2007) Rebound Tonometry in a Clinical Setting. Comparison with Applanation Tonometry. Archivos De La Sociedad Espanola De Oftalmologia, 82, 273-278.

[17] Sahin, A., Niyaz, L. and Yildirim, N. (2007) Comparison of the Rebound Tonometer with the Goldmann Applanation Tonometer in Glaucoma Patients. Clinical \& EXperimental Ophthalmology, 35, 335-339. https://doi.org/10.1111/j.1442-9071.2007.01451.x

[18] Munkwitz, S., Elkarmouty, A., Hoffmann, E.M., Pfeiffer, M. and Thieme, H. (2008) Comparison of the ICare Rebound Tonometer and the Goldmann Applanation Tonometer over a Wide IOP Range. Graefe's Archive for Clinical and Experimental Ophthalmology, 246, 875-879. https://doi.org/10.1007/s00417-007-0758-3

[19] Chui, W.S., Lam, A., Chen, D. and Chiu, R. (2008) The Influence of Corneal Properties on Rebound Tonometry. Ophthalmology, 115, 80-84. https://doi.org/10.1016/j.ophtha.2007.03.061

[20] Rehnman, J.B. and Martin, L. (2008) Comparison of Rebound and Applanation Tonometry in the Management of Patients Treated for Glaucoma or Ocular Hypertension. Ophthalmic and Physiological Optics, 28, 382-386. https://doi.org/10.1111/j.1475-1313.2008.00571.x

[21] Pakrou, N., Gray, T., Mills, R., Landers, J. and Craig, J. (2008) Clinical Comparison of the ICare Tonometer and Goldmann Applanation Tonometry. Journal of Glaucoma, 17, 43-47. https://doi.org/10.1097/IJG.0b013e318133fb32

[22] Van der Jagt, L.H. and Jansonius, N.M. (2005) Three Portable Tonometers, the TGDc-01, the ICARE and the Tonopen XL, Compared with Each Other and with Goldmann Applanation Tonometry. Ophthalmic and Physiological Optics, 25, 429-435. https://doi.org/10.1111/j.1475-1313.2005.00318.x

[23] Poostchi, A., Mitchell, R., Nicholas, S., Purdie, G. and Wells, A. (2009) The ICare 
Rebound Tonometer: Comparison with Goldmann Tonometry, and Influence of Central Corneal Thickness. Clinical \& Experimental Ophthalmology, 37, 687-691. https://doi.org/10.1111/j.1442-9071.2009.02109.x

[24] Martinez-de-la-Casa, J.M., Garcia-Feijoo, J., Castillo, A. and Garcia-Sanchez, J. (2005) Reproducibility and Clinical Evaluation of Rebound Tonometry. Investigative Ophthalmology \& Visual Science, 46, 4578-4580.

https://doi.org/10.1167/iovs.05-0586

[25] Martinez-de-la-Casa, J.M., Jimenez-Santos, M., Saenz-Frances, F., Matilla-Rodero, M., Mendez-Hernandez, C., Herrero-Vanrell, R., et al. (2011) Performance of the Rebound, Noncontact and Goldmann Applanation Tonometers in Routine Clinical Practice. Acta Ophthalmologica, 89, 676-680.

https://doi.org/10.1111/j.1755-3768.2009.01774.x

[26] Davies, L.N., Bartlett, H., Mallen, E.A.H. and Wolffsohn, J.S. (2006) Clinical Evaluation of Rebound Tonometer. Acta Ophthalmologica Scandinavica, 84, 206-209. https://doi.org/10.1111/j.1600-0420.2005.00610.x

[27] Brusini, P., Salvetat, M.L., Zeppieri, M., Tosoni, C. and Parisi, L. (2006) Comparison of ICare Tonometer with Goldmann Applanation Tonometer in Glaucoma Patients. Journal of Glaucoma, 15, 213-217. https://doi.org/10.1097/01.ijg.0000212208.87523.66

[28] Diaz, A., Yebra-Pimentel, E., Resua, C.G., Gilino, J. and Giraldez, J. (2008) Accuracy of the ICare Rebound Tonometer in Glaucomatous Eyes with Topical Ocular Hypotensive Medication. Ophthalmic and Physiological Optics, 28, 29-34. https://doi.org/10.1111/j.1475-1313.2007.00526.x

[29] Marini, M., Da Pozzo, S., Accardo, A. and Canziani, T. (2011) Comparing Applanation Tonometry and Rebound Tonometry in Glaucomatous and Ocular Hypertensive Eyes. European Journal of Ophthalmology, 21, 258-263. https://doi.org/10.5301/EJO.2010.5767

[30] Jorge, J., Fernandes, P., Queiros, A., Ribeiro, P., Garces, C. and Gonzalez-Meijome, J.M. (2010) Comparison of the IOPen and ICare Rebound Tonometers with Goldmann Tonometer in a Normal Population. Ophthalmic and Physiological Optics, 30, 108-112. https://doi.org/10.1111/j.1475-1313.2009.00697.x

[31] Zetterström, C., Behndig, A., Kugelberg, M., Montan, P. and Lundström, M. (2015) Changes in Intraocular Pressure after Cataract Surgery: Analysis of the Swedish National Cataract Register Data. Journal of Cataract \& Refractive Surgery, 41, 1725-1729. https://doi.org/10.1016/j.jcrs.2014.12.054

[32] Avitabile, T., Longo, A., Rocca, D., Amato, R., Gagliano, C. and Castaing, M. (2010) The Influence of Refractive Errors on IOP Measurement by Rebound Tonmetry (ICare) and Goldmann Applanation Tonometry. Graefe's Archive for Clinical and Experimental Ophthalmology, 248, 585-591. https://doi.org/10.1007/s00417-009-1176-5

[33] Song, Y., Congdon, N., Li, L., Zhou, Z., Choi, K., Lam, D.S., et al. (2008) Corneal Hysteresis and Axial Length among Chinese Secondary School Children: The Xichang Pediatric Refractive Error Study (X-PRES) Report No. 4. American Journal of Ophthalmology, 145, 819-826. https://doi.org/10.1016/j.ajo.2007.12.034 